\title{
The Role of Adhesive Forces and Mechanical Interaction on Material Transfer in Hot Forming of Aluminium
}

\author{
Jaume Pujante $^{1 *}$, Montserrat Vilaseca ${ }^{1}$, Daniel Casellas ${ }^{1}$, Maria Dolors Riera ${ }^{1,2}$ \\ ${ }^{1}$ Fundació CTM Centre Tecnològic, Plaça de la Ciència 2, 08243 Manresa. \\ ${ }^{2}$ Department of Materials Science and Metallurgical Engineering, Universitat Politècnica de Catalunya, Avda. \\ Bases de Manresa 61, 08242 Manresa \\ *Corresponding author: Jaume Pujante (jaume.pujante@ctm.com.es).
}

\begin{abstract}
In this work, the mechanisms resulting in transfer of aluminium on hot forming tools have been analysed by means of two separate laboratory tests. The influence of chemical affinity in aluminium adhesion has been studied in contact tests, measuring the force used in pulling at low velocity an aluminium ball pressed against a tool surface. The role of mechanical interaction has been investigated through ball-on-disk sliding tests at high temperature, using tool steel disks with different surface finish against an aluminium counterpart.

These tests have been used for the evaluation of different strategies in adhesive wear reduction, including different tool steels and surface modification, and to study the effect of surface finish on the material transfer mechanisms observed.
\end{abstract}

Keywords: High Temperature; Material transfer; Metal forming; Wear 


\section{INTRODUCTION}

There is a strong trend in increasing the use of aluminium, particularly in the automotive and transport industry [1]. Aluminium-based alloys present some attractive properties over ferrous alloys, such as low density, corrosion resistance, thermal and electrical conductivity and good recyclability, in exchange for reduced mechanical properties and fatigue behaviour. Warm and hot forming processes, such as forging, extrusion, hot sheet metal forming and high pressure die casting can be used to obtain complex-shaped components with good mechanical properties [2].

However, these processes subject the tools to severe tribological solicitations, mainly related to the adhesion of aluminium on the tooling: for instance galling will appear already at room temperature due to the effect of frictional heating [3], and soldering is common in die casting [4]. This results in increased tooling maintenance costs, lower component quality and overall reduced process efficiency.

Several authors have studied the phenomena involved in material transfer in aluminium forming, in test setups with a wide range of levels of complexity and abstraction. In previous work, the authors studied material transfer at different temperatures in reciprocating sliding in a ball-on-disk configuration [5]. Heinrichs et al studied the role of surface defects as adhesion initiation sites through crossed cylinder tests at room temperature [6]. Pellizzari investigated galling in aluminium extrusion at temperatures up to $500^{\circ} \mathrm{C}$ using complex experimental setups [7]. All of these works reached similar results, even though the experimental systems used varied significantly.

One of the strategies proposed to reduce adhesion is the application of surface engineering techniques. The most common options in hot forming are CVD or PVD coatings, able to resist temperatures, pressure and wear. Ni et al [8] studied the effect of a DLC film on material transfer at various temperatures. Vilaseca et al [4] studied material transfer in a series of ball-on-disk tests, including the evaluation of a $\mathrm{CrN}$ coating. In both cases, coatings were able to reduce material transfer, but experiments were limited to flat surfaces with controlled surface finish. The effect of surface finish has also been identified as relevant. For instance, Menezes et al [9] studied the effect of roughness on the friction coefficient generated in unidirectional sliding; results showed that surface deformation and ploughing significantly contributed to the frictional force.

All of these works reach a common conclusion: material transfer is a complex phenomenon, result of the interaction of very different micromechanisms. On the one hand, chemical interaction between aluminium and its 
counterpart leads to adhesive forces, and results in soldering or smearing of adhered layers. On the other hand, mechanical interaction between the two surfaces may also result in material transfer from the softest counterpart to the hardest. Design of solutions and adhesion reducing strategies need to take into account the complex combination of both factors, but the tests performed are not able to isolate the contribution of each one.

In this work, the contribution on overall material transfer of chemical-metallurgical adhesion and mechanical interaction are isolately evaluated. For the first, adhesive forces generated in a static condition were measured for different surface materials; for the latter, ball-on-disk rotary sliding tests were used to identify the main wear micro-mechanisms. While studied systems are an approximation to aluminium hot forming, both the test setup and the main results can be extrapolated to a wide range of tribological systems.

\section{METHODOLOGY}

\subsection{Test equipment and procedure}

Tests were performed on a Bruker CETR UMT-2 tribometer. Thee equipment included a high temperature test chamber including closed loop, computer controlled resistance heating elements. Tests were performed in normal (oxygen-containing) atmosphere. The chosen configuration was ball-on-disk, using tool steel disks as lower specimen and $4 \mathrm{~mm}$ 99\% aluminium balls as upper specimen.

Studies in this work were not intended as accurate reproductions of the wear mechanisms in industrial systems involving aluminium-tool steel contact, but rather as an evaluation of the separate contributions of chemical/adhesive forces and mechanical interaction. In order to do so, two different test modalities were designed: the first one, to test the influence of chemical-metallurgical adhesion on material transfer; the second one, to test the contribution of surface finish.

Test temperature was selected based on previous works. In the one hand, Vilaseca et al [4] determined $450{ }^{\circ} \mathrm{C}$ to be optimal for studying material transfer in aluminium ball on tool steel disk tests. On the other hand, studies leading to work [5] revealed a complex coexistence of abrasive and adhesive wear mechanisms in sliding tests at this temperature. Finally, Jerina and Kalin [10] observed increased Aluminium adhesion in the $300-500^{\circ} \mathrm{C}$ range in 
a series of crossed-cylinder tests. Therefore, $450{ }^{\circ} \mathrm{C}$ was deemed an interesting temperature range to study the isolated contribution of different mechanisms on material transfer. In both configurations, tool steel disk samples were mounted in a holder inside the furnace and brought to temperature in a linear heating ramp of 20 minutes, necessary to stabilize the temperature of the system. Afterwards, ball sample holder was introduced in the test chamber, and allowed $120 \mathrm{~s}$ for heating before beginning the tests.

In order to study adhesion under normal load, the test chamber was heated to $450{ }^{\circ} \mathrm{C}$. The upper sample holder, holding the aluminium ball, descended slowly until it contacted the lower specimen. A normal load of $10 \mathrm{~N}$ was then applied, and kept for 5 s. Afterwards, the upper specimen holder was retracted at a velocity of $50 \mu \mathrm{m} / \mathrm{s}$. This resulted in a linear discharge curve as long as the upper specimen kept a compressive load on the lower sample. In the moment that the contact was lost, force would drop to zero if there was no adhesion force. However, if the ball was adhered to the surface, a peak of tensile force would be registered.

In the case of sliding tests, configuration was based on previous research [4], with some modifications. Tests were performed on a ball-on-rotary disc configuration at $450{ }^{\circ} \mathrm{C}$. The $4 \mathrm{~mm}$ aluminium ball was pressed against the tool steel disk with $3 \mathrm{~N}$ normal load and slid at a velocity of $50 \mathrm{~mm} / \mathrm{s}$. Different test durations were selected. Short tests 50 cycles long were intended to identify the first acting material transfer mechanisms. Tests 500 cycles long were performed to study how material transfer evolved after these first stages.

\subsection{Materials}

For the measurement of adhesive forces, related to chemical affinity between the tool surface and the aluminium counterpart, tool steel samples from different materials were prepared.

Disks 40 mm in diameter were prepared, ground and polished to an arithmetic average roughness Ra under 0.1 $\mu \mathrm{m}$. Samples A, D, E and F were obtained from tool steel DIN 1.2367, sample B was manufactured from tool steel 1.2344. In both cases, material was austenitised at $1080^{\circ} \mathrm{C}$, air cooled and subject to two tempering cycles of $2 \mathrm{~h}$ at $580^{\circ} \mathrm{C}$. This resulted in hardness of $52 \pm 1 \mathrm{HRC}$. 
Sample C was obtained from HTCS130, a special high thermal conductivity tool steel developed by the manufacturer Rovalma S.A., heat treated to a hardness of 52 HRC through a company proprietary process. Previous work with this family of steels suggested that they could be used to reduce adhesion [4].

Additional treatments were applied on samples D, E and F, in order to evaluate different wear-reducing approaches from surface technology. Some authors, such as Pelcastre et al [10a] proposed nitriding as a valid method for reducing adhesive wear: Sample D was subject to a gas nitriding process and re-polished in order to eliminate white layer. Sample E was coated with a commercial PVD AlCrN coating. Finally, sample F was sprayed with a commercial graphite-based hot forming lubricant, diluted in distilled water in a 1:4 proportion. Application was done using compressed air at 2.5 bar, after heating the sample at $500{ }^{\circ} \mathrm{C}$. The result was a homogeneous layer of solid lubricant, approximately $15 \mu \mathrm{m}$ thick and well adhered on the sample surface. For better clarity, this information is summarized in table 1.

\begin{tabular}{ccc}
\hline Sample & Material & Description \\
\hline A & 1.2367 & - \\
B & 1.2344 & - \\
C & HTCS130 & High Thermal Conductivity steel \\
D & $1.2367 \mathrm{Nit}$ & Gas Nitrided \\
E & $1.2367 \mathrm{AlCrN}$ & PVD AlCrN coating \\
F & $1.2367 \mathrm{Lub}$ & Graphite lubricant \\
\hline
\end{tabular}

Table 1: Samples used for the study of adhesive forces

In order to evaluate the influence of surface finish, disks $40 \mathrm{~mm}$ in diameter and $5 \mathrm{~mm}$ thick with different surfaces were prepared from tool steel 1.2367 (table 2). Sample $\mathrm{A}_{0.1}$ was ground using SiC paper, and later polished to Ra under $0.1 \mu \mathrm{m}$. Sample $\mathrm{A}_{0.8}$ was coarse ground using grit $80 \mathrm{SiC}$ paper. The resulting surface had $0.8 \mu \mathrm{m}$ Ra roughness, and random texture. Sample $\mathrm{A}_{2.8}$ was machined (milled) to obtain a patterned surface finish with Ra $2.8 \mu \mathrm{m}$, representative of industrial tooling. 


\begin{tabular}{ccc}
\hline Sample & Roughness Ra & Description \\
\hline $\mathrm{A}_{0.1}$ & $<0.1 \mu \mathrm{m}$ & Ground and polished \\
$\mathrm{A}_{0.8}$ & $0.8 \mu \mathrm{m}$ & Coarse ground, random texture \\
$\mathrm{A}_{2.8}$ & $2.8 \mu \mathrm{m}$ & Milled, patterned surface
\end{tabular}

Table 2: Samples with different surface finish used in sliding tests

In both experiment configurations, $99 \%$ aluminium balls $4 \mathrm{~mm}$ in diameter were used as a counterpart. Hardness of these balls was measured as $51 \pm 5 \mathrm{HV} 1$ at room temperature.

\subsection{Analysis of the samples}

Wear tracks on tool steel samples were inspected by means of Field Emission Scanning Electron Microscopy (FE/SEM). Backscatter Electron imaging (SEM/BSE) allowed clear identification of material transfer.

\section{RESULTS AND DISCUSSION}

\subsection{Influence of chemical adhesive forces}

The test configuration described in section 2.1 was used to isolate the contribution of chemical-metallurgical interaction in adhesive wear and material transfer. Figure 1 a shows a complete discharge curve for one test on tool steel 1.2367, presenting the measured normal force along the displacement in the z-axis. Normal load linearly reduced as the upper specimen holder retracted. When the upper and lower samples were separated, a tensile load peak appeared. Figure $1 \mathrm{~b}$ shows data corresponding only to the tensile peak; test time has been converted to upper specimen displacement. The aluminium-tool steel junction resisted until an elongation of approximately 45 $\mu \mathrm{m}$ was reached, corresponding to a tensile load of 2.2 N. At this moment, the junction failed and load dropped to 
zero. The wavy signal registered after this moment is simply related to the vibration of the spring-mounted specimen carrier after the ball was released.

Samples were observed after the test. Tool steel disks showed reddish colouring, consistent with oxidation during the exposure at $450{ }^{\circ} \mathrm{C}$. Measurement of aluminium balls after the test showed flattened surface on the contact point, as could be expected due to the relative low hardness of the material compounded by the high temperature of the test. Measurements of the flattened contact point showed a rounded contact area approximately $500 \mu \mathrm{m}$ in diameter, resulting in an effective contact pressure in the $50 \mathrm{MPa}$ range.

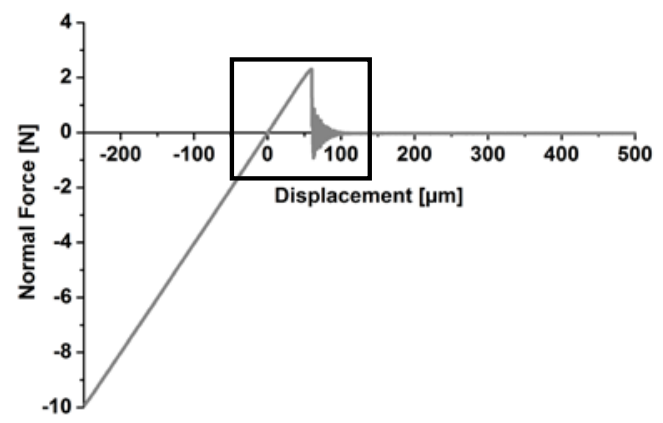

a)

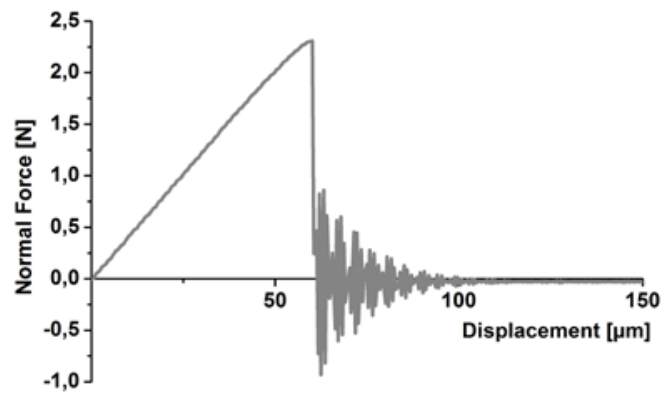

b)

Fig. 1: a) Typical Force-Displacement curve obtained in adhesion tests. Curve obtained for steel 1.2367. b) Detail of the tensile peak detected during retraction, related to ball-disk adhesion forces.

This test procedure was applied on samples A to F, with two repetitions on each sample. Results of the tests are presented in figure 2 a through f, figure 3 presents a summary of the peak forces measured. 

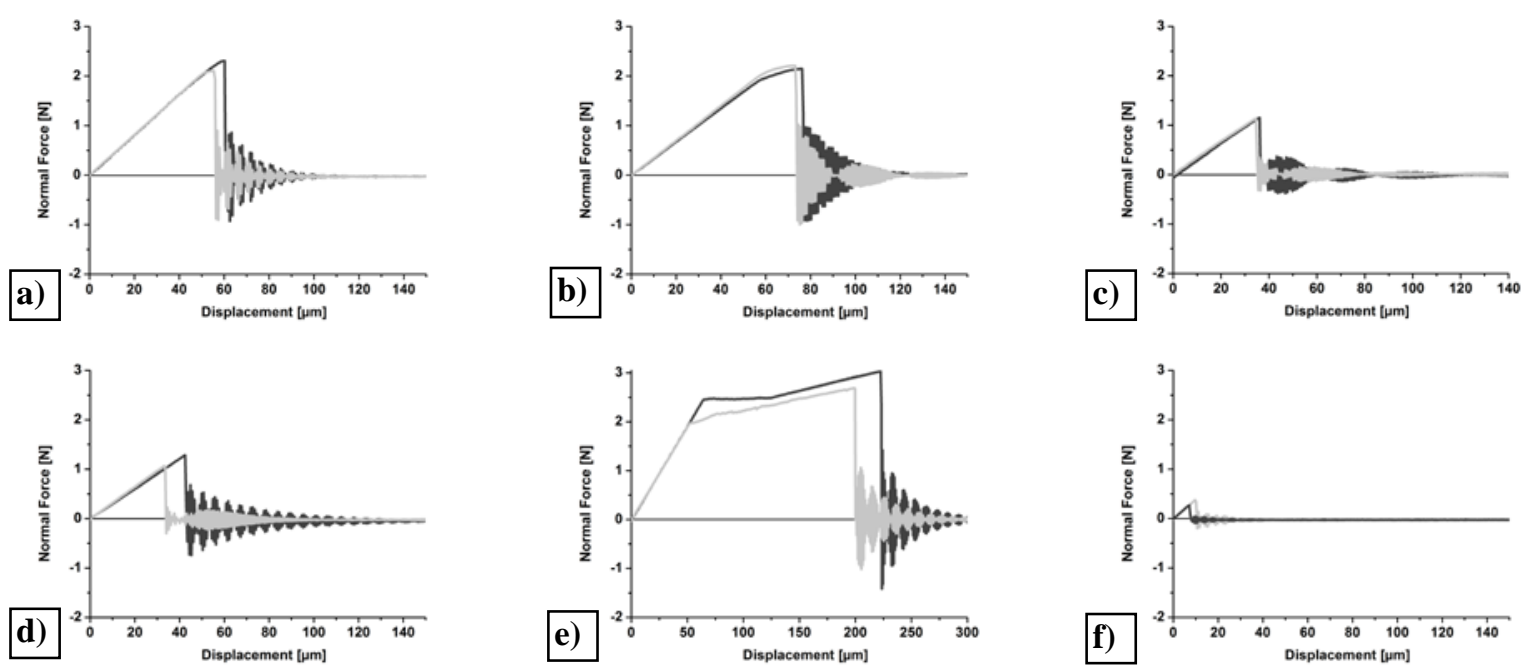

Fig. 2: Force-displacement curves generated during upper specimen retraction for different surfaces: a) 1.2367; b) 1.2344; c) High thermal conductivity steel HTCS130; d) Gas Nitrided 1.2367; e) AlCrN coated tool steel; f) Graphite-lubricated 1.2367.

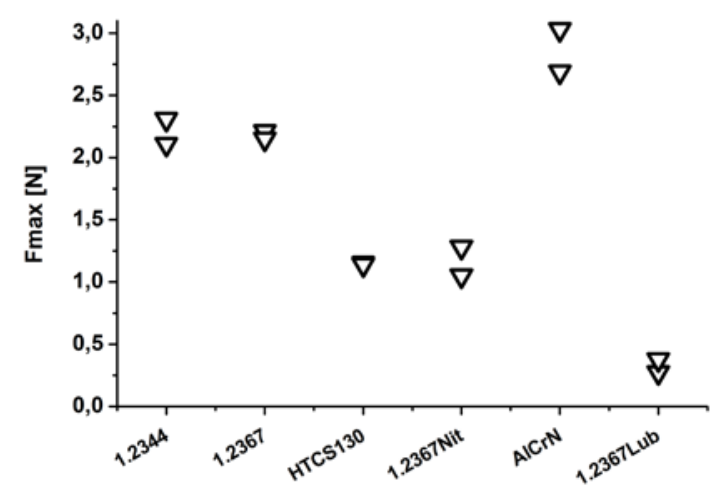

Fig. 3: Maximum tensile forces registered for each material.

Results obtained for tool steel 1.2367 (figure 2 a) and 1.2344 (figure 2 b) are mostly equivalent. In both cases, peak force is very similar, around $2.2 \mathrm{~N}$ and the test showed good repeatability. It can be observed that the elongation is somewhat higher for 1.2344, but this does not reflect in higher peak force (figure 3). Adhesion 
forces measured on High Thermal conductivity steel HTCS130 (figure 2 c) were notably lower than on conventional tool steels 1.2367 and 1.2344. This result offers good correlation with the work of Vilaseca et al [4], where tool steels from the HTCS brand showed reduced aluminium adhesion on ball-on-disc tests compared to tool steel 1.2344 .

Nitriding (figure $2 \mathrm{~d}$ ) appears to reduce adhesion forces. Results obtained on contact test against gas nitrided 1.2367 are consistently lower than 1.2367 without treatment. This should be related to the formation of an oxide layer on top of the surface: after heating to the test temperature of $450{ }^{\circ} \mathrm{C}$, nitrided samples developed a black coloration consistent with post-oxidation. Subsequent EDX analysis confirmed high presence of oxygen on the sample surface. These results can be compared to the work by Pelcastre et al [11], who studied the tribological behaviour of Al-Si-coated boron steel sliding against nitrided tool steel. These authors report that the formation of oxides on top of the tool steel surface appeared to reduce material transfer, particularly noticeable in nitrided tool steel subject to a post-oxidation treatment.

AlCrN-coated samples (figure 2 e) show higher adhesion force than the uncoated tool steels. Maximum tensile force is significantly higher (over 2.6 N, see figure 3), and the junction breaks only after significant elongation (more than $200 \mu \mathrm{m}$ ). Tests also showed worse repeatability. Inspection of this sample after experiments showed a small volume of aluminium adhered on the contact point, showing that fracture had not happened in the interface, but inside the volume of aluminium. The junction created is therefore very strong, stronger at least that pure aluminium at the testing temperature. These results suggest that application of this coating could be detrimental in terms of aluminium adhesion in absence of other wear and damage mechanisms. It is difficult to compare these results with previous experiences in the open literature. Similar observations were drawn by Pelcastre et al [11], in sliding tests against Al-Si coated Ultra-High Strength Steel, AlCrN-coated specimens increased the amount of material adhesion, which authors relate to chemical affinity. However, it must be taken into account that the chemical composition of the hardened Boron steel coating mainly consists of Al-Si-Fe intermetallics, as opposed to metallic aluminium [12].

Finally, as could be expected, the application of a graphite-based lubricant (figure $2 \mathrm{f}$ ) greatly reduced adhesion. Contact between the aluminium ball and the coated sample was ended with a very small force peak (around 0.3 N). Observation of the samples after test showed presence of graphite on both counterparts: the lubricant coating had not been completely pulled from the tool steel surface, but the aluminium counterpart also showed graphite 
residues. This indicates that the graphite layer had effectively avoided direct metal-to-metal interaction, and that shearing in the interface had taken place inside the layer of graphite.

\subsection{Sliding tests and influence of surface finish}

The sliding test setup described in section 2.1 was applied to study the effect of surface finish. After testing, samples were studied by means of Scanning Electron Microscopy. Figure 4 shows images corresponding to wear tracks generated after 50 sliding cycles.
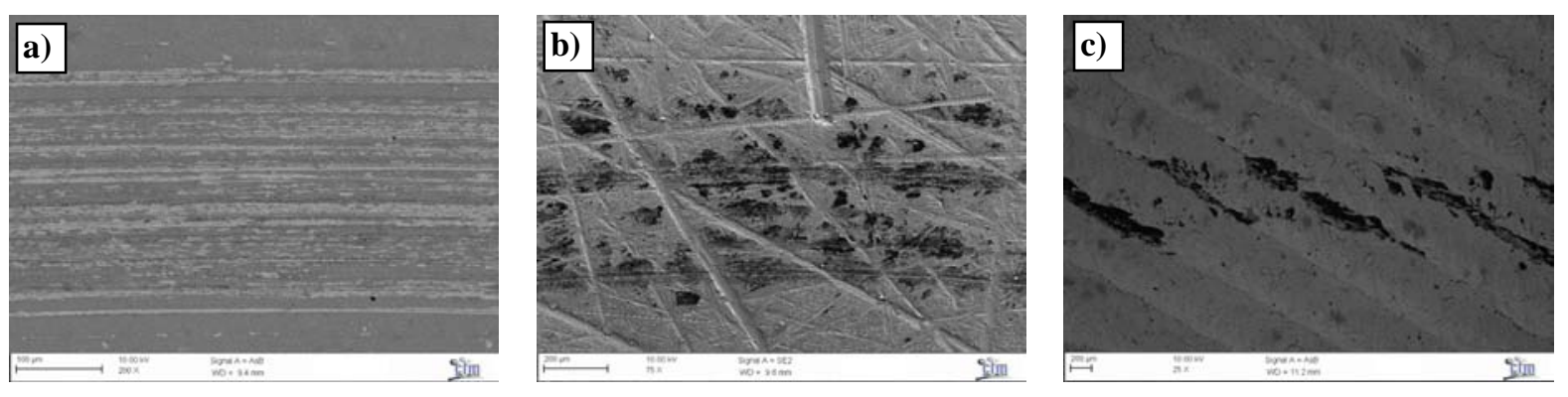

Fig. 4: Overview of the wear tracks generated after 50 cycles: a) polished sample; b) ground sample; c) machined sample. Darkest phases correspond to transferred aluminium.

\subsubsection{Tests on polished samples}

Low magnification SEM/BSE inspection of the wear track on polished material revealed very low overall amount of material adhesion (figure 4 a). Moreover, the main wear mechanism observed was abrasive: removal of the first layer of oxides on the tool steel surface and formation of thin grooves. This material removal appeared in the form of lines parallel to the contact sliding direction. As the ball material (99\% aluminium) is very soft at $450{ }^{\circ} \mathrm{C}$, formation of these scratches can only be related to the formation of hard particles of oxidized aluminium, that become trapped inside the contact possibly even embedding themselves in the ball. Similar observations were drawn on earlier work by the same authors [5] in reciprocating contact of aluminium alloy against tool steel. 
Detailed inspection of the wear track (figure 5 a) showed that some material transfer had appeared in two forms: very thin layers of smeared material and small lumps of material adhered in the edges of the abrasion grooves formed.
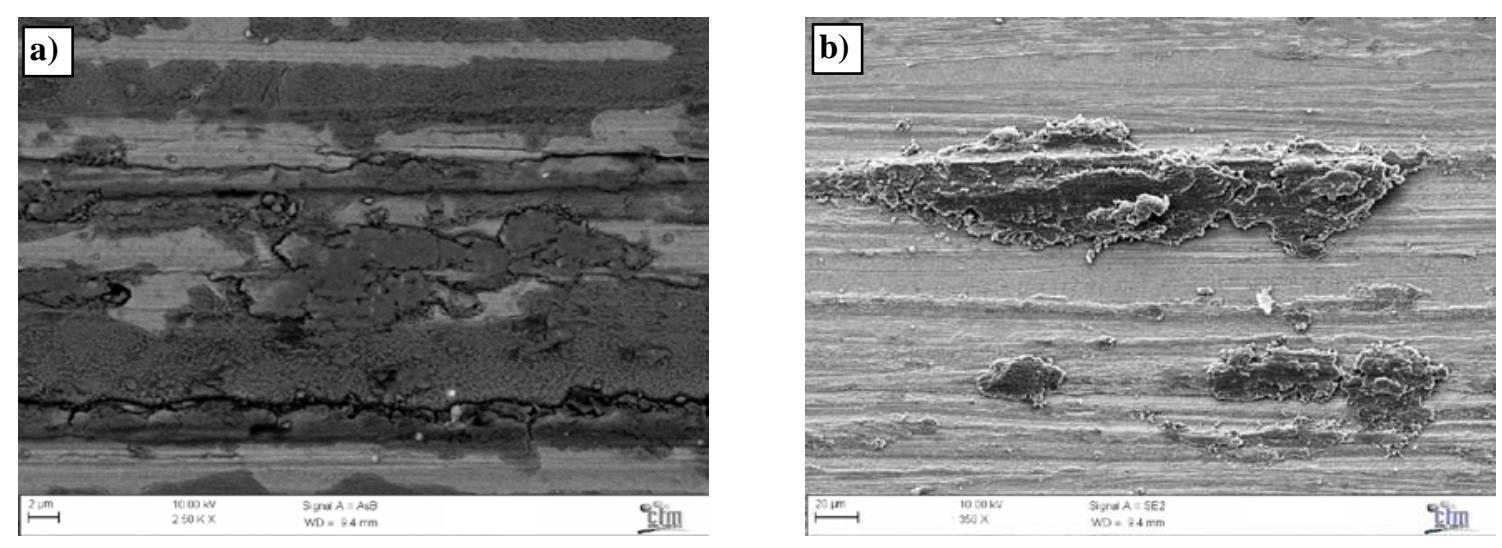

Fig. 5: SEM/BSE high magnification detail of the wear track on polished samples. a) After 50 sliding cycles. b) After 500 sliding cycles. Bright lines correspond to zones where the topmost oxide layer had been abraded. Dark globular shapes correspond to transferred aluminium.

Observation of the wear track after 500 cycles (figure 5 b) revealed a much higher amount of transferred material. However, material transfer appeared as large, isolated patches of aluminium on various points of the wear track. These patches appear to be formed by layers of material accumulated along the cycles, growing from a nucleation point. Abrasion, however, does not appear to have progressed further from the grooves observed after 50 cycles.

Based on this analysis, it appears that material transferred in polished samples happened through mainly mechanical interaction: in the first cycles mostly abrasive mechanisms took place, resulting in the generation of nucleation points on the tool steel surface. Along the following cycles, these nucleation points sticking from the otherwise flat surface would plough the softer aluminium ball, mechanically removing a small volume of material that remained attached to the nucleation site. The net result would be the growth of small nucleation points into large isolated adhesion patches. It is also possible that some potential nucleation points were removed by the abrasive action of aluminium oxide particles formed during sliding. 
These results are consistent with the work of Vilaseca et al [4], who reported material transfer in tool steel samples taking the shape of isolated patches of aluminium, instead of material uniformly adhered on the wear track. It is also consistent with results obtained in previous work on reciprocating sliding [5], showing a coexistence of adhesive and abrasive wear mechanisms, and accumulation of aluminium-based material transfer on surface irregularities. On the other hand, authors Jerina and Kalin [10] obtained slightly different results in a series of single-pass crossed-cylinder tests contacting aluminium alloy and hot work tool steel H13. As in the current work, they observed the formation of a thin smeared layer over the tool steel surface. However, they also observed the stochastic formation of adhesive lumps, and no abrasion. The current work presents a multi-pass test with the aim of identifying mechanical interaction; this can explain the different presence of abrasive mechanisms compared to reference [10], consisting on single pass tests. It is also possible that adhesion spots formed in the first test cycles are polished away in the following contact cycles.

\subsubsection{Tests on ground samples}

Low magnification analysis of the wear track showed higher amount of aluminium transfer than polished samples after 50 cycles (figure 4 b). Importance of abrasion-based mechanisms also appeared to be greatly reduced.

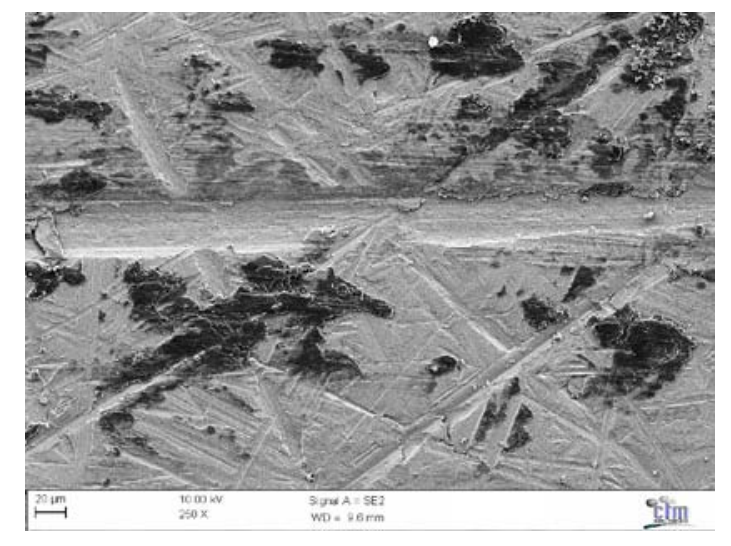

Fig. 6: SEM/BSE detail of the wear track on a ground sample after 50 sliding cycles. Material transfer initiated on surface grooves, abrasion grooves could be observed on flat surfaces. 
Observation of the surface at higher magnifications (figure 6) revealed that grooves on the surface acted as nucleation sites, due to mechanical interaction with the ball. Due to the high density of such points on the tool steel surface, the distribution of material transfer was relatively homogeneous.

Abrasive wear mechanisms, similar to the mechanisms observed on polished samples, were observed only the flattest surface areas (plateaus with only shallow grooves situated between deep marks). This suggests that potentially abrasive particles are removed from the contact by becoming trapped on the deep grooves in the pattern. Given that free debris was not observed in a significant amount after the test, it is possible that these particles have been lumped together with adhered material.

\subsubsection{Tests on machined samples}

On samples with a defined milling pattern, material transfer accumulated only at the highest peaks of the pattern, indicating that the main mechanism acting was, again, ploughing from the harder tool steel peaks on the softer aluminium ball (figure 4 c).
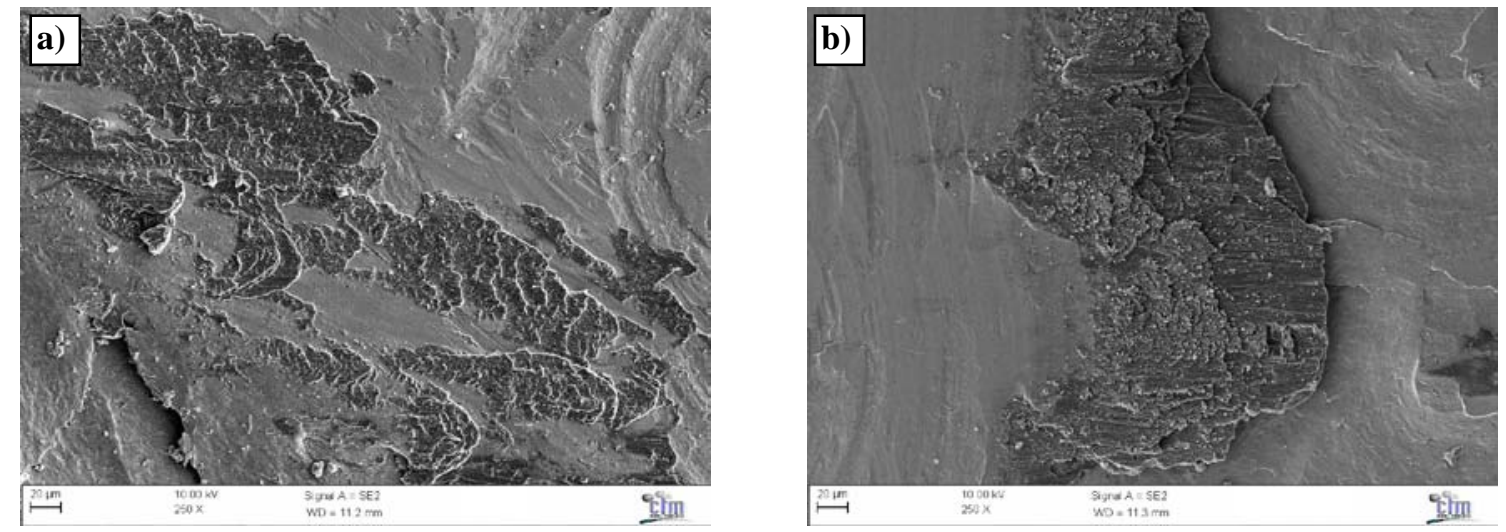

Fig. 7: SEM/BSE details of the wear track on machined samples; darker phases correspond to aluminium adhesion. a) After 50 sliding cycles. b) After 500 sliding cycles. 
It must be noticed that almost all material transfer remained at the high points of the pattern, where it had first been ploughed; that is, material did not flow or fall into the valleys of the pattern (figure 7 a).

After 500 cycles, the total amount of transferred material had increased, but the mechanism remained the same. Adhesion patches grew by adding more aluminium to the material already transferred on previous cycles. Even though the total amount of material transfer increased, it concentrated on the same zones where aluminium had transferred in the first 50 cycles (figure 7 b).

\subsubsection{Tests on polished, AlCrN-coated samples}

Finally, pre-polished, AlCrN-coated samples were studied using the sliding test setup described in section 2.1. The aim of this test was to evaluate the effect of increased chemical adhesion and higher surface hardness on the dominating material transfer mechanisms. Figure 8 shows a SEM/BSE image of the wear track.
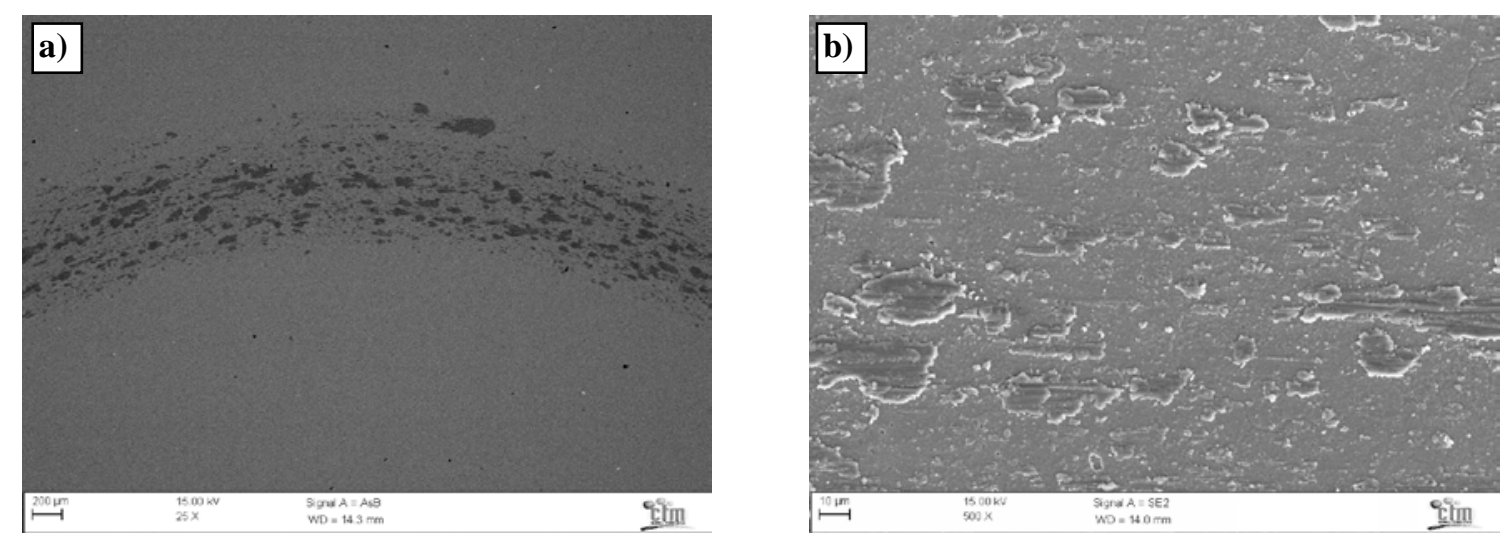

Fig. 8: SEM/BSE images of the wear track on a polished, PVD-coated sample after 50 sliding cycles; darker phases correspond to aluminium adhesion. a) Overview; b) Detail of the wear track.

Material transfer mechanisms observed differed from non-coated samples (figure 5). Abrasive wear mechanisms were not observed on the wear track. Formation through abrasion mechanisms of new material transfer nucleation points is unlikely, due to the high hardness of the coating. Material transfer could be observed in the form of 
evenly distributed little lumps of adhered material, covering a large portion of the wear track. This indicates that dominating mechanisms were based in chemical affinity.

This observation is consistent with the results described in section 3.1 and displayed on Figure 2 e. It is also consistent with the observations of Pelcastre et al [11], who observed increased galling in sliding AlCrN-coated and TiAlN-coated samples against heat treated ultra-high strength steel, containing high $\mathrm{Al}$ in the coating. This increased material transfer is explained by these authors through the high temperature and $\mathrm{Al}$ contained in both counterparts. This consideration can be used to explain the discrepancies between the present work and results by Vilaseca [4], showing reduced adhesion on PVD CrN-coated specimens.

\section{CONCLUSIONS}

In this work, the phenomenon of material transfer of aluminium on hot forming tools has been studied from two isolated points of view: chemical and metallurgical interaction between the surfaces and mechanical interaction related to surface finish. While the tests presented do not attempt to reproduce wear mechanisms in the industrial systems, useful information was obtained and the following conclusions could be drawn:

- A test for measurement of adhesive interaction was developed. This test was successfully used to measure the adhesion forces between aluminium and six different surfaces at high temperature.

- $\quad$ Chemical affinity was very similar for the two tool conventional steels studied: 1.2367 and 1.2344. High thermal conductivity steel HTCS 130 almost halved adhesive force compared to conventional tool steel.

- $\quad$ Out of the proposed wear reduction strategies, application of a solid lubricant layer was the most effective in reducing adhesive forces. Nitrided tool steel showed reduced adhesive forces, probably related to the formation of a surface oxide layer. On the contrary, even though it avoids direct metal-tometal contact, application of a hard AlCrN PVD coating resulted in increased adhesive forces.

- $\quad$ Sliding tests on non-coated samples showed material transfer originated by mechanical interaction on surface irregularities. In polished samples, it began on features generated by material removal mechanisms. On ground and machined samples, material adhered on the edges of surface features. 
- Abrasive wear mechanisms were observed on sliding tests on polished samples. These mechanisms were less important on ground samples, and not present in machined surfaces.

- Sliding tests on PVD-coated samples showed that material transfer changed from being mechanicallydominated as in uncoated samples to being based on chemical affinity.

- $\quad$ Both chemical and mechanical interactions contributed to the phenomenon of material transfer.

\section{ACKNOWLEDGEMENTS}

This investigation has been partially funded by the Catalan government under grants TECCTA-13-1-0005 and TECCTA-14-0005. J. Pujante also acknowledges the support received from the Commission for Universities and Research of the Department of Innovation, Universities and Enterprise of the Catalan government under the scholarship 2010TEM24.

\section{REFERENCES}

[1] Miller, W.S., Zhuang, L., Bottema, J., Wittebrood, A.J., De Smet, P., Haszler, A., Vieregge, A.: Recent development in aluminium alloys for the automotive industry. Materials Science and Engineering A 280, 37-49 (2000)

[2] Hanna, M. D.: Tribological evaluation of aluminium and magnesium sheet forming at high temperatures. Wear 267, 1046-1050 (2009)

[3] Groche, P., Nitzsche, G.: Influence of temperature on the initiation of adhesive wear with respect to deep drawing of aluminium-alloys. Journal of Materials Processing Technology 191, 314-316 (2007)

[4] Vilaseca, M., Molas, S., Casellas, D.: High Temperature Tribological Behaviour of Tool Steels During Sliding against Aluminium. Wear 272, 105-109 (2011) 
[5] Pujante, J., Pelcastre, L., Vilaseca, M., Casellas, D., Prakash, B.: Investigations into wear and galling of aluminium alloy-tool steel tribopair at different temperatures. Wear 308, 193-198 (2013)

[6] Heinrichs, J., Jacobson, S.: The influence from shape and size of tool surface defects on the occurrence of galling in cold forming of aluminium. Wear 271, 2517-2524 (2011)

[7] Pellizzari, M.: High temperature wear and friction behaviour of nitrided, PVD-duplex and CVD coated tool steel against $6082 \mathrm{Al}$ alloy. Wear 271, 2089-2099 (2011).

[8] Ni, W., Cheng, Y., Weiner, A.M., Perry, T.A.: Tribological behavior of DLC coatings against aluminium alloys at elevated temperature. Surf. Coat. Technol. 201, 3229-3234 (2006)

[9] P. Menezes, S Kishore, V Kailas, Studies on friction and transfer layer: role of surface texture. Tribol. Lett. 24 (2006) 265-273

[10] Jerina, J., Kalin, M.: Initiation and evolution of the aluminium-alloy transfer on hot-work tool steel at temperatures from $20^{\circ} \mathrm{C}$ to $500^{\circ} \mathrm{C}$. Wear $319,234-244$ (2014)

[11] Pelcastre, L., Hardell, J., Prakash, B.: Galling mechanisms during interaction of tool steel and Al-Si coated ultra-high strenth steel at elevated temperature. Tribology International 67, 263-271 (2013)

[12] Grigorieva, R., Drillet, P., Mataigne, J.M., Barges, P.: Study of Phase Transformations in Al-Si Coating During the Austenitization Step. In: 8th International Conference on Zinc and Zinc Alloy Coated Steel Sheet GalvaTech 2011, 21-24 June 2011 in Genova, Italy, Paper 10. 